\title{
Inibidores de corrosão para estruturas de concreto armado: uma revisão
}

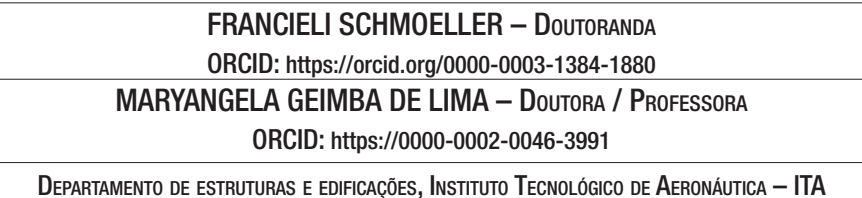

\section{RESUMO}

DENTRE AS MANIFESTAÇÕES PATOLÓGICAS QUE DEGRADAM AS ESTRUTURAS DE CONCRETO ARMADO, A CORROSÃO DA ARMADURA É UMA DAS MAIS PREOCUPANTES. A CORROSÃO RESULTA NA DETERIORAÇÃO DO MATERIAL E DE SUAS PROPRIEDADES, AFETANDO SIGNIFICATIVAMENTE A DURABILIDADE E A VIDA ÚTIL DA ESTRUTURA, ALÉM DE DESPENDER UM ALTO CUSTO COM RECUPERAÇÃO. OS INIBIDORES DE CORROSÃO SÃO CONSIDERADOS UM DOS MELHORES MÉTODOS DESTINADOS À PROTEÇÃO DO AÇO, SENDO CAPAZES DE CRIAR UM FILME PASSIVADOR NA SUA
SUPERFÍCIE, DE POSTERGAR O PROCESSO DE INICIAÇÃO DA CORROSÃO E TAMBÉM DE REDUZIR A TAXA DE CORROSÃO. EXISTEM DIFERENTES INIBIDORES QUE PODEM SER APLICADOS E SÃO CONSIDERADOS ÚTEIS NÃO APENAS COMO UMA MEDIDA PARA NOVAS ESTRUTURAS, MAS TAMBÉM COMO PREVENTIVO E RESTAURADOR ADITIVO DE SUPERFÍCIE NO CASO DE ESTRUTURAS EXISTENTES. ASSIM, ESTE ARTIGO BUSCOU TRAZER O ESTADO DA ARTE DOS INIBIDORES DE CORROSÃO QUE VÊM SENDO APLICADOS EM ESTRUTURAS DE CONCRETO ARMADO NOS ÚLTIMOS ANOS.

Palavras-chave: inibidores, corrosão, concreto armado.

\section{INTRODUÇÃO}

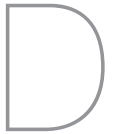

entre as manifestações patológicas em estruturas de concreto armado, a corrosão de armaduras é a mais recorrente e preocupante, pois pode ocasionar a ruptura parcial ou total da estrutura. Além disso, a corrosão apresenta um alto índice de custos não planejados, e sua recuperação é delicada, requerendo mão de obra especializada. Assim sendo, devido à grande utilização do concreto armado como sistema estrutural em todo o mundo, a sua durabilidade deve ser um fator importante na avaliação de um projeto, de forma a garantir condições mínimas de segurança, estabilidade e funcionamento.

Com o intuito de mitigar a cor- rosão, existem diversas medidas de proteção aplicáveis, como a implementação de inibidores de corrosão, que Gentil (2011) relata ser um dos métodos mais utilizados, tanto de forma preventiva como corretiva. Os inibidores são substâncias químicas encontradas em diferentes composições que atuam nas reações eletroquímicas anódica e catódica. Ainda, podem ser empregados como aditivo durante o amassamento do concreto ou via migração, no caso de ser aplicado na superfície do concreto já endurecido.

Todavia, para a eficácia dos inibidores, faz-se necessário um concreto de boa qualidade, correta previsão da agressividade do meio ambiente, estrutura projetada corretamente e condições operacionais adequadas, a fim de garantir um bom desempenho do sistema.

Outrossim, na recuperação de estruturas em processo de corrosão, é indicado avaliar as causas da corrosão no sistema, identificando corretamente a origem dessa manifestação patológica, afim de utilizar um inibidor de corrosão que corresponda com as propriedades e mecanismos de ação necessárias. Além disso, é necessário entender o funcionamento correto do material, de sua composição química e da concentração mínima a ser empregada, para que o produto não tenha efeito contrário ao esperado.

Várias pesquisas tiveram como objetivo um melhor entendimento do 
funcionamento dos inibidores, da influência no processo corrosivo e da busca por novos materiais com ação inibidora, o que nos últimos anos teve como foco principal os chamados inibidores verdes. Este artigo buscou trazer o estado da arte dos inibidores de corrosão que vêm sendo aplicados em estruturas de concreto armado.

\section{CORROSÃO EM ESTRUTURAS DE CONCRETO ARMADO}

A camada passivadora, uma fina película protetora de óxidos e hidróxidos que se forma na superfície da barra em ambiente alcalino no concreto, é responsável por proteger a armadura da corrosão (HELENE, 1986; LIMA, 1996). Entretanto, esse filme de passivação não é indestrutível e pode ser decomposto quimicamente, propiciando o início do processo corrosivo.

Em meio aquoso, a corrosão da armadura acontece por um processo eletroquímico com reações de oxidação e redução, formando uma corrente elétrica e uma corrente iônica. Com isso, geram-se duas regiões distintas na superfície do metal: a zona anódica, onde ocorrerá a oxidação, e a zona catódica, que irá reduzir os íons hidrogênio e o oxigênio presentes no eletrólito (ANDRADE, 1992). Um modelo da célula de corrosão é ilustrado na Figura 1.

Ressalta-se que as reações de oxirredução acontecem simultaneamente, ou seja, a oxidação (perda de elétrons) e a redução (ganho de elétrons) ocorrem ao mesmo tempo. Ainda, duas fases ocorrem: de iniciação, quando da penetração de agentes agressivos até o momento que

a armadura é despassivada, e de propagação, por meio da perda de seção que pode ocorrer com a presença de oxigênio e umidade.

Outro fator importante para a corrosão é o $\mathrm{pH}$ do meio. Quando o $\mathrm{pH}$ do con-

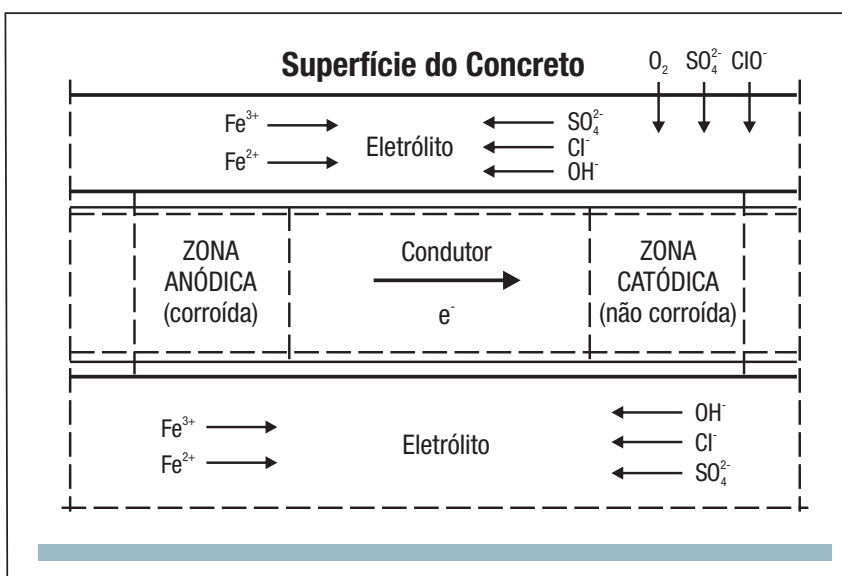

Figura 1

Modelo simplificado de célula de corrosão

Fonte: adaptado de Helene (1986) creto passa a

ser menor que 11,5, a película passivadora é destruída, o que propicia o início da corrosão. No diagrama de Pourbaix, são estabelecidas as condições de $\mathrm{pH}$ em relação ao potencial que leva o material à corrosão, à passivação ou que o faz permanecer imune, como mostra a Figura 2.

Outrossim, existem fatores que aceleram a corrosão em estruturas de concreto armado, como a lixiviação, carbonatação, meios ácidos, reação álcali-agregado, salinidade da água do mar, porosidade, fissuras, dentre outros.

Mediante a vasta utilização desse sistema estrutural, a durabilidade deve ser um fator importante na avaliação de um projeto, para manter condições mínimas de segurança, estabilidade e funcionamento.

Dentre as formas de prevenir a corrosão, destaca-se a utilização de cimentos resistentes a sulfato e cloreto, de materiais compostos com polímeros, revestimentos protetores, remoção de cloreto e realcalinização, assim como o uso de inibidores, que têm sido aplicados e considerados um dos melhores métodos 
destinados à proteção do aço (GENTIL, 2011).

\section{INIBIDORES DE CORROSÃO}

Os inibidores de corrosão são produtos químicos que, quando presentes em concentração adequada no meio corrosivo, protegem a armadura através da formação de uma camada de óxidos na sua superfície, ou reduzem a velocidade de corrosão por meio da recuperação da camada passivadora, sem modificar muito a concentração do agente agressivo (LIMA, 1996).

Estas substâncias são capazes de retardar a atividade eletroquímica da reação anódica (por meio de inibidores anódicos), da reação catódica (via inibidores catódicos) ou de ambas as reações (com uso de inibidores mistos), rompendo o circuito eletroquímico formado pela célula de corrosão. Para a aplicação em concreto, os inibidores devem ser ativos em meio alcalino e não devem alterar substancialmente as propriedades físicas, químicas e mecânicas do concreto (HELENE, 1986; ANDRADE, 1992).

Em estruturas de concreto armado, os inibidores são considerados úteis não apenas como uma medida preventiva à corrosão, mas também como aditivo de superfície restaurador. Em novas construções, os inibidores são adicionados na mistura do concreto fresco, de modo a estender o tempo de iniciação da corrosão e/ ou reduzir a taxa de corrosão após a despassivação da armadura. Em construções existentes, podem ser misturados em argamassas e concretos de reparo, e são aplicados na superfície do concreto ou instalados em sulcos para acelerar sua difusão.
Contudo, os inibidores via adição são considerados mais confiáveis, fáceis e seguros de aplicar.

\section{I Classificação dos inibidores}

Os inibidores podem ser classificados de acordo com sua composição química, mecanismo de proteção e meio de aplicação. Lima (1996), Gentil (2011) e Venkatesh et al. (2019) expõe as classificações mais conhecidas como descrito na sequência.

\section{I.I COMPOSIÇÃO QUÍMICA}

Em relação a composição química, Shi et al. (2009) divide os inibidores em:

a) orgânicos: agem formando uma película protetora no aço, que inibe as reações anódicas e catódicas dos processos de corrosão, e obstrui o acesso de cloretos e oxigênio - as aminas e os carboxilatos são exemplos de inibidores orgânicos usados em concreto armado.

b) inorgânicos:

> estudos mostraram a eficiência do fosfato de sódio em inibir a corrosão por pite, se sua concentração for igual à concentração de cloreto, embora sua eficiência seja parcialmente perdida no concreto; > o nitrito de cálcio modifica as propriedades químicas superficiais do aço e comporta-se como um acelerador de pega e de endurecimento, podendo atingir melhores resistências à compressão;

$\checkmark$ o nitrito de sódio é muito eficaz e não altera significativamente as propriedades físico-quími- cas do concreto, embora tenha estudos indicando seus efeitos prejudiciais para a resistência à compressão, além de estimular a corrosão por pites, com o aumento da temperatura.

c) naturais: atualmente há uma tendência de estudos voltados a materiais sustentáveis, buscando reduzir ao máximo os resíduos e utilizando com eficiência os materiais e bens naturais relacionado aos inibidores de corrosão, há diversas pesquisas recentes direcionadas à eficiência dos inibidores verdes, desde extratos de folhas, cascas, frutos e sementes de plantas (como exemplo, o extrato de gengibre e o óleo de palmeira têm apresentado bom desempenho na resistência à corrosão, além de serem ecologicamente corretos).

\section{I.2 MECANISMO DE PROTEÇÃO}

Em relação ao mecanismo de proteção, os inibidores de corrosão podem ser divididos em (VENKATESH et al., 2019):

a) inibidores anódicos: atuam reprimindo a reação do anodo, criando um filme aderente na superfície da barra e aumentando a polarização anódica - são divididos em dois tipos de inibidores de passivação:

> íons não oxidantes, que requerem presença de oxigênio para passivar o aço;

$\checkmark$ ânions oxidantes, com os quais a passivação ocorre sem a presença de oxigênio;

$\checkmark \quad$ as principais substâncias utilizadas como inibidores anódicos 
são os molibdatos, nitratos, cromatos, ortofosfatos e benzoatos.

b) inibidores catódicos: atuam reprimindo a reação do catodo, através de reações que produzem compostos insolúveis que impedem a difusão do oxigênio e a condução de elétrons; porém, são considerados menos eficientes do que os inibidores anódicos, sendo os mais usados: os carbonatos, silicatos, fosfatos, óxido de zinco e polifosfatos.

c) inibidores mistos: provocam reações inibidoras em ambas as extremidades da célula de corrosão, anódica e catódica - com isso, reduzem a taxa de corrosão, sem mudar significativamente o potencial de corrosão.

Os inibidores catódicos são chamados de inibidores seguros, pois, mesmo com concentração insuficiente, permitem uma corrosão uniforme ao longo da barra, sem causar danos localizados. Já os inibidores anódicos, como os nitritos, são considerados inibidores perigosos, já que, quando em concentração insuficiente para a proteção total do aço, podem provocar uma corrosão localizada, que, muitas vezes, agrava a situação da anomalia já existente (LIMA, 1996; VENKATESH et al., 2019).

\section{I.3 APLICAÇÃO}

De acordo com Lima (1996), existem duas maneiras de aplicar-se os inibidores de corrosão:

a) via adição: são mistura- dos ao concreto no estado plástico e se conectam eletronicamente com a superfície do aço, formando uma fina camada de proteção.

- os inibidores orgânicos são frequentemente usados na mistura do concreto; entretanto, alguns desses podem alterar a velocidade de hidratação do cimento, causar uma redução na resistência à compressão e aumentar o perigo de reação álcali-agregado; - o nitrito de cálcio acelera a hidratação do cimento, o que requer um retardador de pega

b) via migração: conhecido como $\mathrm{MCl}$ (Migrating Corrosion Inhibitors), são aplicados na superfície externa do concreto endurecido, de modo que o inibidor se infiltra no concreto até atingir a armadura.

- os compostos orgânicos como aminas e carboxílicos são muito populares, e agem reprimindo as reações catódica e anódica, na mistura.

formando um filme na interface concreto-aço;

- os inorgânicos, como o monoflurofosfato de sódio, são geralmente utilizados para mitigar o início do desgaste ou diminuir a taxa de corrosão.

\subsection{Fatores determinantes na escolha do inibidor}

Os fatores que determinam a escolha do inibidor de corrosão são: tipo do metal, composição, pH, temperatura, facilidade de mistura, impurezas e custo. Gentil (2011) destaca que a eficiência na utilização dos inibidores de corrosão depende de quatro aspectos, listados a seguir:

a) as causas da corrosão no sistema, identificando o problema;

b) o custo da sua utilização;

c) as propriedades e os mecanismos de ação dos inibidores de corrosão;

d) condições adequadas de adição e controle.

Ainda, para os inibidores anódicos, a aplicação da quantidade adequada para a proteção é de fundamental importância, pois se o inibidor apresentar valor abaixo da concentração crítica, o produto insolúvel e protetor não se forma em toda a extensão da superfície da barra, gerando frente para a corrosão localizada nas áreas não protegidas.

A Figura 3 compara a Concentração inicial em água aerada, para a inibição provocada no ferro, comparando íons molibdato $\left(\mathrm{MoO}_{4}{ }^{2-}\right)$, tungstato ( $\left.\mathrm{WO}_{4}{ }^{2-}\right)$, cromato $\left(\mathrm{CrO}_{4}{ }^{2-}\right)$ e nitrito $\left(\mathrm{NO}_{2}\right)$

Fonte: Lima (1996) apud Robertson (1951) ação de quatro diferentes inibidores em relação a uma concentração inicial 
mínima para sua efetividade contra a corrosão.

Nota-se que, para os quatro inibidores em análise na Figura 3, a concentração inicial deve ser de $10^{-3}$ mols/litro para apresentar eficiência contra o processo corrosivo. Além disso, ao atingir o valor de $10^{-6}$ mols/ litro na concentração, a taxa de corrosão é similar à do metal imerso em água destilada, indicando que a concentração iônica na superfície do metal é importante, assim como as propriedades químicas dos íons aplicados como agentes oxidantes.

Salienta-se ainda que outra dificuldade é de avaliar a performance dos inibidores em estruturas reais "in loco". A interpretação das medidas de potencial de corrosão, usadas para avaliar o desempenho do inibidor, pode ser dificultada, pois a estrutura encontra-se em um ambiente não controlado, podendo haver alterações na umidade e resistividade do concreto ou devido à presença de pares redox alternativos induzidas pela substância inibidora.

\section{CONCLUSÕES}

Os inibidores são produtos eficientes na prevenção da corrosão, através da formação de uma película passivadora na superfície da barra, postergando a iniciação da corrosão e reduzindo a velocidade de corrosão por meio da recuperação dessa camada protetora.

A maioria dos inibidores demonstram impactos positivos no concreto fresco e endurecido. Aminas, alcanolaminas e carboxilatos são inibidores mistos usados principalmente em concreto armado. Já os inibidores via migração $(\mathrm{MCl})$ são importantes no reforço de estruturas deterioradas devido à entrada de íons cloreto no concreto, e o monoflurofosfato de sódio é comumente utilizado. Os nitritos e nitratos aceleram a pega do concreto fresco, onde o mesmo número de ácidos carboxílicos tende a dificultar a taxa de hidratação do cimento.

Os extratos de plantas, muito pesquisados nos últimos anos, são considerados uma fonte incrivelmente rica de inibidor de corrosão ambientalmente aceitável. Inúmeros produtos naturais foram testados como inibidores de corrosão para diferentes metais em vários ambientes. Dentre esses estudos utilizando inibidores naturais, também chamados de "green inhibitors", o extrato de gengibre e o óleo de palmeira têm apresentado eficiência e bom desempenho na resistência à corrosão.

Entretanto, é essencial aplicar uma concentração inicial adequada. Se o produto insolúvel e protetor não se formar em toda a extensão da superfície da barra pode gerar frente para a corrosão localizada e agravar ainda mais o processo. Outro fator importante é determinar a escolha do inibidor em relação ao tipo do metal, às condições do meio e à origem do problema.

\section{AGRADECIMENTOS}

Os autores gostariam de agradecer as instituições: Coordenação de Aperfeiçoamento de Pessoal de Nível Superior - CAPES pelo financiamento do projeto e ao Instituto Tecnológico de Aeronáutica - ITA pelo apoio institucional e técnico.

\section{DREFERÊNCIAS BIBLIOGRÁFICAS}

[1] ANDRADE, C. Manual para diagnóstico de obras deterioradas por corrosão de armaduras. São Paulo: Pini, 1992

[2] ASAAD, M. A. et al. Enhanced corrosion resistance of reinforced concrete: Role of emerging eco-friendly Elaeis guineensis/silver nanoparticles inhibitor. Construction and Building Materials, n. 188, p. 555-568, 2018.

[3] GENTIL, V. Corrosão. 6 ed. Rio de Janeiro: LTC, 2011.

[4] HELENE, P.R.L. Corrosão em armaduras para concreto armado, São Paulo, Ed. Pini,1986.

[5] LIMA, M. G. Inibidores de corrosão: avaliação da eficiência frente à corrosão de armaduras provocada por cloretos. Tese de Doutorado. Escola Politécnica da Universidade de São Paulo (USP). São Paulo, 1996.

[6] POURBAIX, M. Atlas of electrochemical equilibria in aqueous solutions. Brussels: CEBELCOR, 1974.

[7] SHI X. et.al. An electrochemical and microstructural characterization of steel-mortar admixed with corrosion inhibitors. Science in China, Series E: Technological Sciences, v. 52, n. 1, p. 52-66, 2009.

[8] SIVAKUMAR, P. R.; SRIKANTH, A. P. Green corrosion inhibitors: a comparative study. Sādhanā, n. 56, 2020.

[9] VENKATESH, C., et al. Corrosion Inhibitors Behaviour on Reinforced Concrete - A Review. In: Das B., Neithalath N. Sustainable Construction and Building Materials. Lecture Notes in Civil Engineering, vol 25. Singapore: Springer, 2019.

[10] WANG, W., et al. Employing ginger extract as an eco-friendly corrosion inhibitor in cementitious materials. Construction and Building Materials, n. 228, 2019. 